\title{
Cox-2 inhibition enhances the activity of sunitinib in human renal cell carcinoma xenografts
}

\author{
X Wang ${ }^{1,2}$, L Zhang ${ }^{2}$, A O'Neill ${ }^{3}$, B Bahamon ${ }^{4}$, D C Alsop ${ }^{1}$, J W Mier ${ }^{2}$, S N Goldberg ${ }^{1,5}$, S Signoretti ${ }^{4}$, \\ M B Atkins ${ }^{6}, C$ G Wood ${ }^{7}$ and R S Bhatt ${ }^{\star}, 2$
}

${ }^{1}$ Department of Radiology, Beth Israel Deaconess Medical Center, Harvard Medical School, 330 Brookline Avenue, Boston, MA 02215, USA; ${ }^{2}$ Division of Hematology-Oncology and Cancer Biology, Beth Israel Deaconess Medical Center, Harvard Medical School, 330 Brookline Avenue, Boston, MA 02215, USA; ${ }^{3}$ Department of Biostatistics and Computational Biology, Dana-Farber Cancer Institute, 450 Brookline Avenue, Boston, MA 02215, USA; ${ }^{4}$ Department of Pathology, Brigham and Women's Hospital, Harvard Medical School, 75 Francis Street, Boston, MA 02115, USA; ${ }^{5}$ Department of Radiology, Hadassah Hebrew University Medical Center, PO Box 12000, Jerusalem 91120, Israel; ${ }^{6}$ Georgetown-Lombardi Comprehensive Cancer Center, 3970 Reservoir Road, NW, Washington, DC 20057, USA and 'Department of Urology, Division of Surgery, The University of Texas MD Anderson Cancer Center, 1515 Holcombe-Unit1373, Houston, TX 77030, USA

Background: Sunitinib (Su), a tyrosine kinase inhibitor of VEGFR, is effective at producing tumour response in clear cell renal cell carcinoma (cRCC), but resistance to therapy is inevitable. As COX-2 is a known mediator of tumour growth, we explored the potential benefit of COX-2 inhibition in combination with VEGFR inhibition in attempts at delaying tumour progression on Su.

Methods: COX-2 expression was compared with areas of hypoxia in tumours that progressed on Su vs untreated tumours. Mice bearing human CRCC xenografts were treated with Su and the COX-2 inhibitor, celecoxib, and the effects on tumour growth were assessed. Sequential vs concurrent regimens were compared.

Results: COX-2 expression was increased in CRCC xenografts in areas of tumour hypoxia. The combination of Su and celecoxib achieved longer times to tumour progression compared to treatment with either agent alone or to untreated control animals in four models. This effect was seen with concurrent but not with sequential therapy.

Conclusion: COX-2 inhibition can extend the effectiveness of VEGFR inhibition. This effect is dependent on the timing of therapy. Clinical trials combining Su and COX-2 inhibitors should be considered as a means delaying time to progression on sunitinib in patients with metastatic cRCC.

Recently, several new agents targeting the VEGF pathway have demonstrated significant activity in patients with advanced clear cell renal cell carcinoma (cRCC). Sunitinib, sorafenib and pazopanib are multi-tyrosine kinase inhibitors (TKI) whose targets include vascular endothelial growth factor receptor-2 (VEGFR2) and their activity is thought to be primarily based on their inhibition of this target. In a first-line phase III trial in patients with metastatic cRCC in which sunitinib was compared with
IFN- $\alpha$, the response rate was $47 \%$ and the median progression-free survival (PFS) was 11 months for sunitinib compared with a $12 \%$ response rate and median PFS of 5 months for IFN- $\alpha$ (Motzer et al, 2009). Similar results were seen in a phase III clinical trial comparing pazopanib to placebo (Sternberg et al, 2010). Axitinib, another VEGFR TKI was recently added to the therapeutic armentarium, while still another, tivozanib is currently under late stage investigation (Rini et al, 2011; Motzer et al, 2012; Nosov et al,

*Correspondence: Dr RS Bhatt; E-mail: rbhatt@bidmc.harvard.edu

Revised 7 December 2012; accepted 7 December 2012;

published online 15 January 2013

(c) 2013 Cancer Research UK. All rights reserved 0007-0920/13

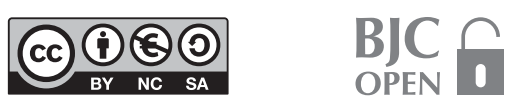


2012). While the beneficial effects of TKIs are significant, strategies to enhance and/or prolong the effect of these agents are of importance as responses are almost exclusively partial and tumours develop tumour progression on therapy at a median of less than 1 year.

The mechanisms of resistance to VEGFR inhibition are not fully understood and have been variably reported to involve restored angiogenesis, inhibition of angiostatic pathways, and induction of angiogenesis independent processes such as increased tumour invasiveness and epithelial-to-mesenchymal transition (Casanovas et al, 2005; Rini and Atkins, 2009; Bhatt et al, 2010; Hammers et al, 2010; Huang et al, 2010). Understanding the mechanism of resistance may not only guide subsequent treatment selection, but may also provide insights into optimal upfront combination treatment approaches.

Cyclooxygenase-2 (COX-2) is an enzyme in the pathway leading to production of prostaglandin E2 (PGE2) and arachadonic acid (Ghosh et al, 2010). This pathway is known to play a role in inflammation, tumour growth, invasiveness and metastasis, inhibition of apoptosis and angiogenesis. Inhibition of COX-2 has been shown to be a promising antitumour and antiangiogenic strategy in several tumour types including RCC (Hida et al, 2000; Song et al, 2002; Chen et al, 2004a; Arber et al, 2006). In preclinical models, COX-2 inhibition has been shown to exhibit activity as a single agent as well as in combination with immunotherapy and chemotherapy (Veltman et al, 2010; Legge et al, 2011; Vivaldi et al, 2012). COX-2 inhibitors have also been studied in combination with interferon- $\alpha$ therapy in patients with advanced cRCC. Although initial reports suggested improved response rates for patients bearing high COX-2 expressing tumours, a subsequent study of the combination of a COX-2 inhibitor and interferon- $\alpha$ confined to this patient population did not substantiate a significant benefit for the combination relative to interferon alone. The value of COX-2 inhibition in combination with VEGFR TKIs has not been formally studied in patients with RCC.

We have previously developed murine models of acquired tumour resistance to VEGFR TKI therapy using human cRCC xenografts. One of these models utilises tumour tissue directly obtained from a patient at the time of nephrectomy for cRCC. The tumour model MDA-62 is a xenograft model of cRCC developed from a tumour fragment harvested from a patient with locally advanced cRCC. Thus, unlike the cell line models that are of clonal origin, this low passage xenograft may better represent tumour heterogeneity noted in the human condition. In this study we explored the role of COX-2 in these models by assessing tumour expression of COX-2 in tumour that have progressed while on sunitinib and studying the effects of the combination of sunitinib and the selective COX-2 inhibitor, celecoxib.

\section{MATERIALS AND METHODS}

Tumour xenograft induction. For subcutaneous xenografts the following models were used: A498, 786-O: human cRCC cell lines (ATCC, Manassas, VA, USA), UMRC-3 (Grossman et al, 1985) and MDA-62 a primary tumour from a patient with locally advanced clear cell RCC that was propagated subcutaneously in mice for three passages prior to cryopreservation (Karam et al, 2011). Female nude beige mice (Charles River Laboratories, Wilmington, MA, USA), 6-8 weeks of age and $20 \mathrm{~g}$ average body weight, were used. The mice were housed and maintained in laminar flow cabinets under specific pathogen-free conditions. All experiments were approved by the Institutional Animal Care and Use Committee (IACUC) at Beth Israel Deaconess Medical Center. To produce tumours, renal cancer cells were harvested from subconfluent cultures by a brief exposure to $0.25 \%$ trypsin and $0.02 \%$ EDTA. Trypsinization was stopped with medium containing $10 \%$ FBS, and the cells were washed once in serum-free medium and resuspended in PBS. Only suspensions consisting of single cells with $>90 \%$ viability were used for the injections.

Cells were injected subcutaneously $\left(1 \times 10^{7}\right.$ cells $)$ into the flanks of the mice. Tumours developed in $>80 \%$ of the mice and were usually visible within a few days of implantation and once they reached a diameter of $3-5 \mathrm{~mm}$, were measured daily to ensure a consistent size at the outset of treatment. Vehicle, sunitinib (additive-free, $53.6 \mathrm{mg} \mathrm{kg}^{-1}$ daily by gavage), celecoxib (50 $\mathrm{mg} \mathrm{kg}^{-1}$ daily by gavage) (Farooqui et al, 2007; Park et al, 2008; Li et al, 2011), or the combination was begun when the tumours had grown to a diameter of $12 \mathrm{~mm}$ as per our previous reports (Bhatt et al, 2010; Zhang et al, 2011). Tumours were measured daily during therapy to determine growth curves.

In all, $12 \mathrm{~mm}$ was used as the pre-specified treatment start size in the 786-O and A498 models in part because this size of tumour may be sufficiently large to be proportionately comparable to a lesion in the human clinical setting, but not too large to prevent a period of several weeks before the mice would need to be sacrificed at the end point of $20 \mathrm{~mm}$ tumour size. It is also an optimal size for tumour perfusion imaging, which is difficult to perform on smaller tumours. Growth by $2 \mathrm{~mm}$ from this baseline is the minimal reproducible change in tumour size that could be accurately measured by our calipers. Time to increase by $2 \mathrm{~mm}$ was defined as time to tumour progression. This approach is roughly equivalent to the increase in tumour size (20\% increase in long axis) that would classify a patient as having progressive disease by RECIST criteria (and therefore, treatment resistance) while receiving such therapy, as it represents a $17 \%$ increase in diameter and $59 \%$ increase in volume. Additionally, in our analysis, the tumour growth curves showed similar results with both tumour volume and long axis measurements (Figures 2A and B). In this model, progression also correlates with the resumption in tumour perfusion that follows an initial reduction in perfusion, seen in our prior studies (SchorBardach et al, 2009; Bhatt et al, 2010).

Treatment was continued until tumours grew to $20 \mathrm{~mm}$ in longaxis diameter (i.e., the maximum allowable growth by IACUC) at which point the mice were sacrificed. Tumour tissue from sunitinib, celecoxib, and untreated tumours was obtained at $20 \mathrm{~mm}$ for various analyses described below. Sunitinib-treated tumours that grew beyond $14 \mathrm{~mm}$ and grew to the end point of $20 \mathrm{~mm}$ size despite continued treatment were defined as 'Resistant to sunitinib'.

In the studies with UMRC-3 and MDA-62, treatment was started when tumours reached a size of $5 \mathrm{~mm}$ in maximum diameter. Tumour size was measured daily and mice were sacrificed after 30 days of treatment. The pretreatment tumour size was less in this model because the study design differed from the xenograft model in which imaging was performed at $12 \mathrm{~mm}$ for optimal imaging resolution.

Immunohistochemistry. For hypoxia analysis, animals were injected intraperitoneally with Hypoxyprobe (Pimonidazole $\mathrm{HCl}$ : Hypoxyprobe store, NPI, Cat \# HP1-100 kit, Burlington, MA, USA) $100 \mu \mathrm{l} 2 \mathrm{~h}$ prior to sacrifice. For COX-2 and Hypoxyprobe analysis, $4 \mu \mathrm{m}$ thick sections were prepared from formalin-fixed, paraffin-embedded tumour specimens. Sections were deparaffinized, rehydrated and heated with a pressure cooker to $125^{\circ} \mathrm{C}$ for $30 \mathrm{~s}$ in citrate buffer for antigen retrieval. After cooling to room temperature, sections were incubated in 3\% hydrogen peroxide for $5 \mathrm{~min}$ to quench endogenous peroxidase, (Dako, Carpinteria, CA, USA). The primary antibodies (anti-COX-2 antibody from Cayman Chemical, Ann Arbour, MI, USA, Cat \#160112; antiHypoxyprobe antibody from Natural Pharmacia International, Burlington, MA, USA, Cat\#FITC-MAb1) were applied at a 1:50 
dilution, to sections for $1 \mathrm{~h}$. Detection was performed by incubation with Dako EnVision + System HRP labelled polymer anti-mouse (Dako, Cat\# K4006) for 30 min followed by incubation with $\mathrm{DAB}$ chromogen. Slides were slightly counterstained with hematoxylin. Slides were scanned using the Scanscope XT (Aperio Technologies Inc., Visa, CA, USA).

Tumour perfusion imaging. Tumour perfusion imaging with arterial spin-labelling MRI (ASL MRI) was performed as previously described (Bhatt et al, 2010). Briefly mice were anaesthetized, and placed in the supine position on a $3-\mathrm{cm}$ diameter custom-built surface coil. Images were acquired using a $3.0 \mathrm{~T}$ whole-body clinical MRI scanner (3 T HD; GE Healthcare Technologies, Waukesha, WI, USA). A single slice ASL image was obtained with a single-shot fast spin echo sequence (SSFSE) using a backgroundsuppressed, flow-sensitive alternating inversion-recovery strategy. Twenty-four label and control pair images were acquired and averaged for the ASL acquisition. A reference proton density image was acquired by turning off all background suppression and labelling pulses in the ASL preparation. T1 measurement was performed by using the same imaging sequence at same slice location but with inversion recovery at different inversion times. The single transverse slice of ASL was carefully positioned at the centre of the tumour, which was marked on the skin with a permanent marker pen for follow-up MRI studies. ASL raw data were reconstructed and converted to quantitative tumour perfusion maps using automated, custom software written within the Interactive Data Language (IDL; ITT visual Information Solutions, Boulder, CO, USA) (Alsop and Detre, 1996). Regional analysis of the perfusion images was performed with Image-J software (Image Processing and Analysis in Java; National Institutes of Health, Bethesda, MD, USA). To determine tumour perfusion, a region of interest was drawn freehand around the peripheral margin of the tumour by using an electronic cursor on the reference image that was then copied to the perfusion image. The mean blood flow for the tumour tissue within the region of interest was derived. A 16-colour table was applied in $10 \mathrm{ml}$ per $100 \mathrm{~g}$ per min increments ranging from 0 to $160 \mathrm{ml}$ per $100 \mathrm{~g}$ per min, with flow values represented as varying shades of black, blue, green, yellow, red, and purple, in order of increasing perfusion.

Statistical analysis. The primary end point was time to progression (TTP). TTP was defined as time in days to increase by $2 \mathrm{~mm}$ in tumour size and compared between groups via the exact Wilcoxon rank sum test. Median TTP in days and ranges are reported throughout.
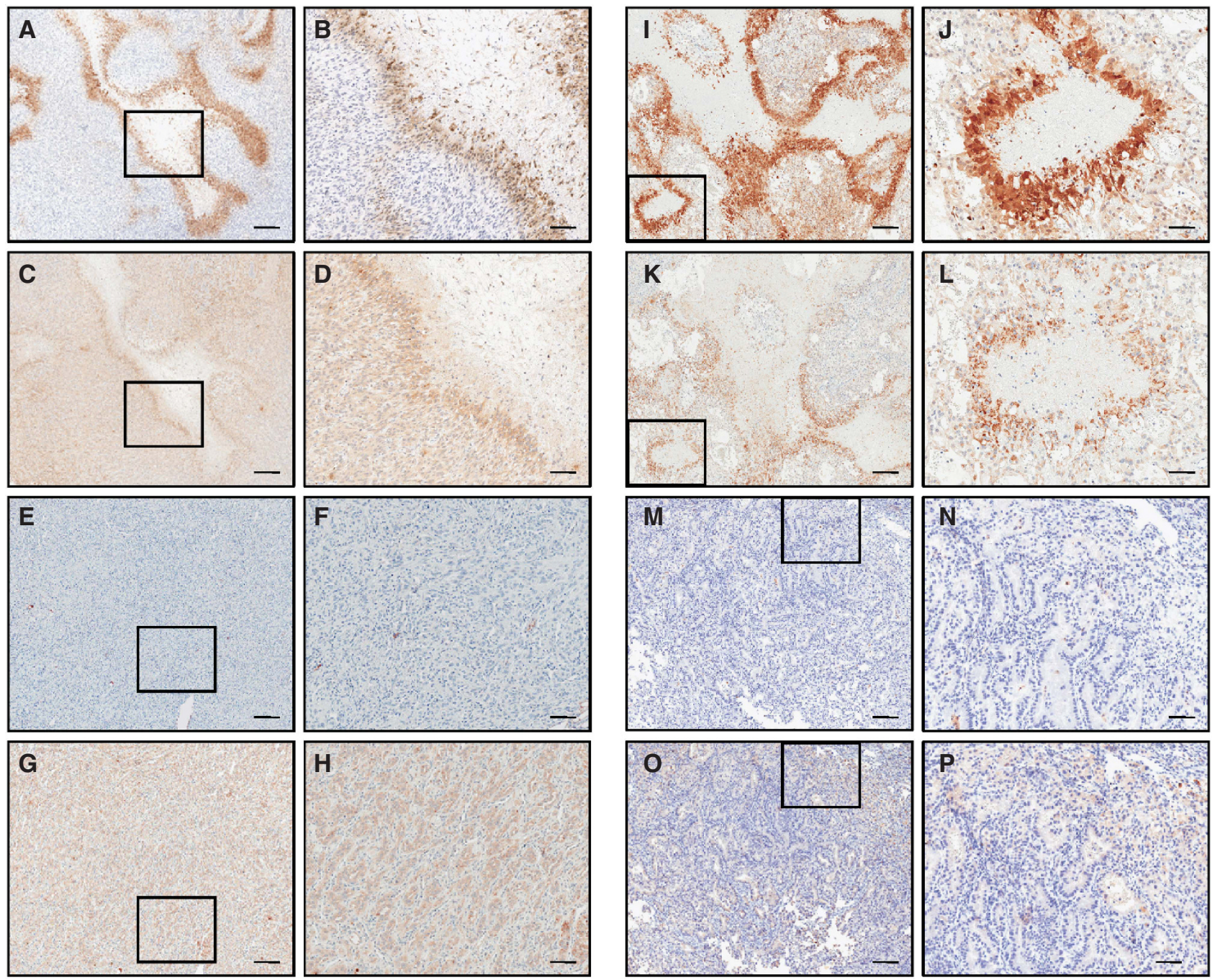

Figure 1. Sunitinib resistance is accompanied by enhanced COX-2 expression in areas of tumour hypoxia. Representative low (A, C, E, G, I, K, M, O) (scale bar $=300 \mu \mathrm{m}$ ) and high (B, D, F, H, J, L, N, P) (scale bar $=100 \mu \mathrm{m}$ ) magnification microscopic images of cRCC xenografts analysed by immunohistochemistry. 786-O tumours treated with sunitinib (A-D) or vehicle $(\mathbf{E}-\mathbf{H})$ and $\mathrm{A} 498$ tumours treated with sunitinib (I-L) or vehicle (M-P) were immunostained for Hypoxyprobe (A, B, E, F, I, J, M, N) or COX-2 (C, D, G, H, K, L, O, P). 


\section{RESULTS}

Sunitinib-treated tumours exhibit enhanced hypoxia which correlates with COX-2 expression. Since sunitinib treatment reduces tumour blood flow (Bhatt et al, 2010; Zhang et al, 2011), we assessed the effect of this agent on tumour hypoxia. We found that sunitinib treatment of either A498 or 786-O tumours leads to tumour hypoxia which is present, as shown in Figure 1, at the time of resistance to sunitinib. Pimonidazole $\mathrm{HCl}$-positive hypoxic tumour cells are consistently observed around areas of tumour necrosis (Figure 1A, B, I, and J) while only scattered hypoxic tumour cells are detected in untreated tumours (Figure 1E, F, M, and $\mathrm{N}$ ). As COX-2 expression is known to be induced by hypoxia, we also assessed the COX-2 expression in suntinib resistant tumours. As shown in Figure 1, both 786-O (Figures 1C and D) and A498 (Figure $1 \mathrm{~K}$ and $\mathrm{L}$ ) suntinib resistant tumours exhibit a spatially regulated area of increased COX-2 expression, with maximal expression in the hypoxic tumour cells surrounding areas of necrosis in 786-O (C,D) and A498 (K,L) tumours. In contrast, consistent with the absence of significant tumour hypoxia, COX-2 expression does not occur in such a specific pattern in vehicletreated tumours of the same size. Untreated tumours did not exhibit hypoxia and showed diffuse COX-2 expression (Figure 1E-H and $\mathrm{M}-\mathrm{P}$ ). Thus, sunitinib resistance is accompanied by an increase in COX-2 expression levels in areas of hypoxic tumour cells.

Combining COX-2 inhibition with sunitinib enhances antitumour efficacy and delays disease progression on sunitinib. We hypothesised that the increased COX-2 expression seen in sunitinib resistant tumours might indicate a role for COX-2 inhibition in enhancing efficacy of and/or delaying tumour progression on sunitinib. Mice harbouring A498 and 786-O xenografts were treated with vehicle, sunitinib, celecoxib, or sunitinib + celecoxib. Figure $2 \mathrm{~A}-\mathrm{C}$ show the tumour growth by tumour volume, length, and time to progression in the four treatment arms in the mice bearing A498 tumours. The
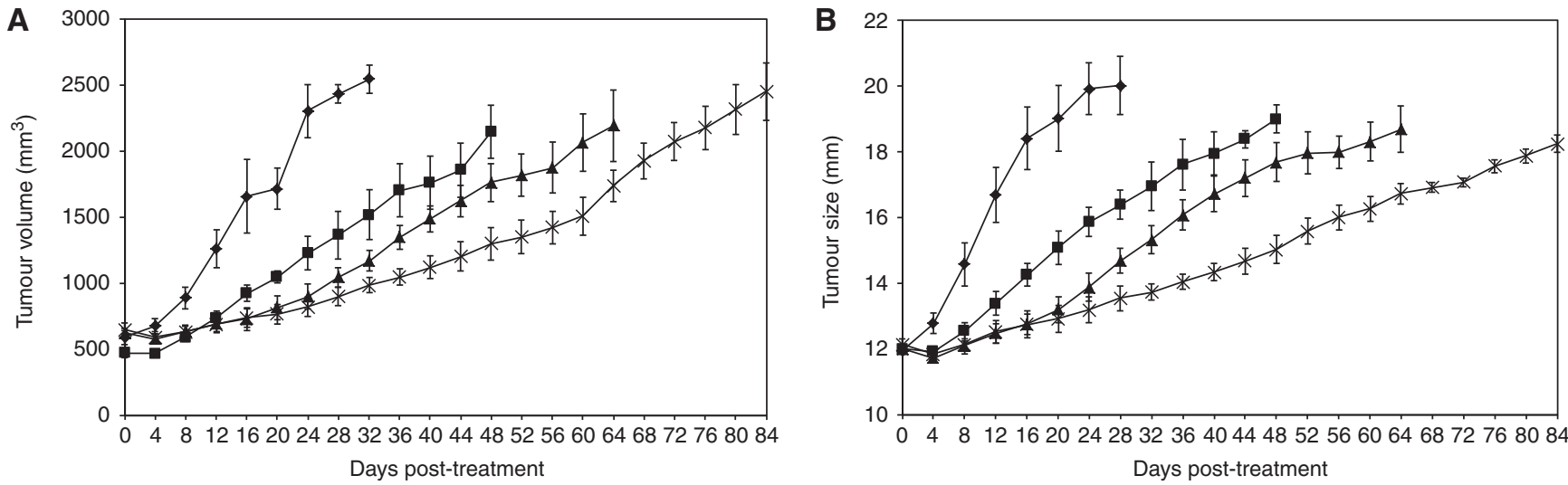

Vehicle $\rightarrow$ Celecoxib $\rightarrow$ Sunitinib $\star$ Celecoxib+sunitinib
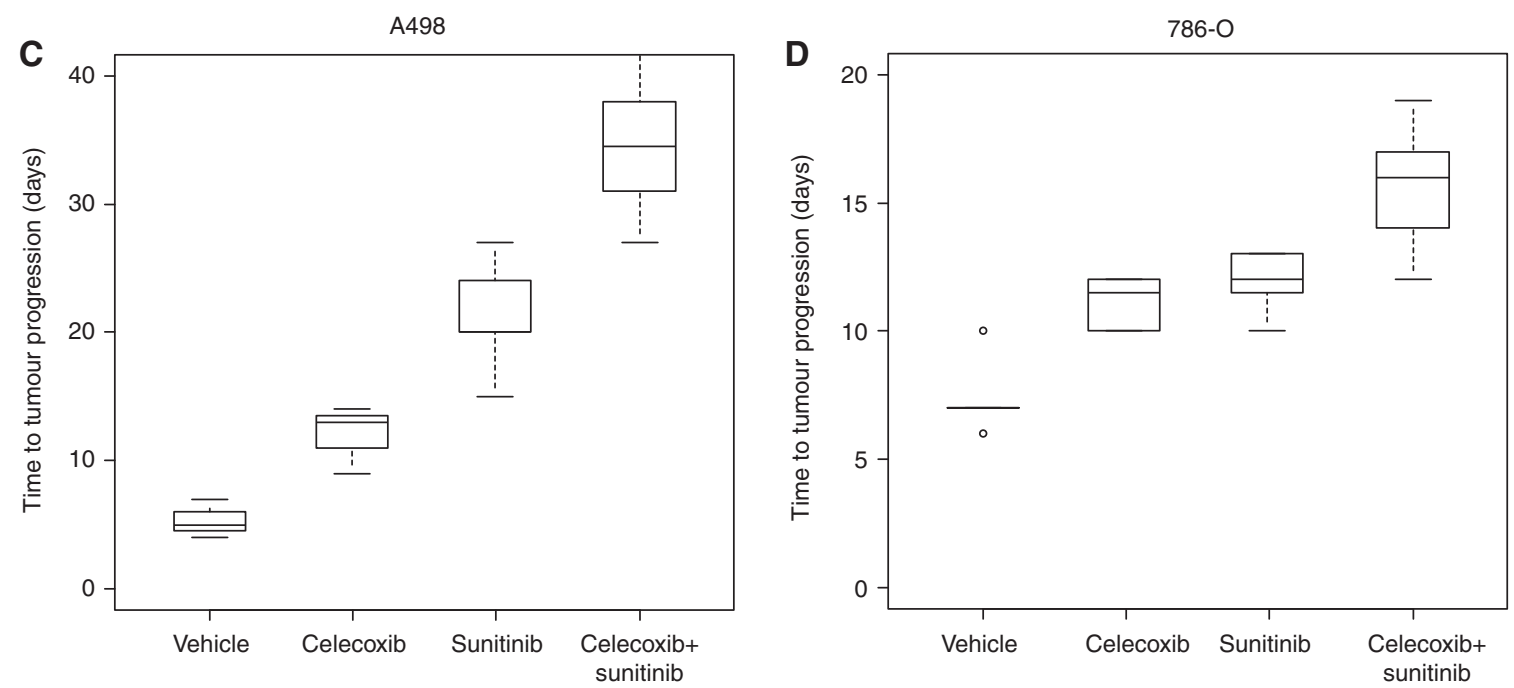

Figure 2. Celecoxib enhances the anti-tumour activity of sunitinib in two cRCC models. Growth curves in tumour volume (A) and tumour size (long axis) (B) of A498 derived tumours treated with vehicle $(n=3)$, sunitinib $(n=5)$, celecoxib $(n=3)$ or celecoxib + sunitinib $(n=6)$ are shown as average \pm s.e.m. (C) In mice bearing the A498 tumour, the combination of celecoxib + sunitinib showed a longer time to progression than treatment with sunitinib alone 34.5 (27-45) days, $n=6$ and 20 (15-27) days, $n=5$, respectively, $P=0.006$ ). (D) Mice bearing 786-O tumours also exhibit a significant prolongation in time to progression with the combination of celecoxib + sunitinib relative to sunitinib alone (16 (12-19) days, $n=7$ and 12 (10-13) days, $n=7$, respectively, $P=0.007$ ). For box plots themselves, the thick horizontal line within each box is the median value; the upper and lower boundaries of the boxes are the 75th and 25th percentiles. The bars above and below the boxes are placed at the observed values closest to the 75 th percentile plus 1.5 times the interquartile range (75th percentile minus 25 th percentile) and closest to the 25 th percentile minus 1.5 times the interquartile range; observations outside those limits are plotted separately and represented with a small circle. 
combination of sunitinib + celecoxib showed a longer time to progression than treatment with sunitinib alone (median (range): 34.5 (27-45) days, $n=6$ vs 20 (15-27) days, $n=5$, respectively, $P=0.006)$. The vehicle arm and the celecoxib single agent arm showed shorter times to progression of 5 (4-7) days, $n=3$ vs 13 (9-14) days, $n=3$. Figure $2 \mathrm{D}$ shows that mice bearing $786-\mathrm{O}$ tumours also exhibit a significant prolongation in time to progression with the combination of sunitinib + celecoxib relative to sunitinib alone (median (range) 16 (12-19) days, $n=7$ vs 12 (10-13) days, $n=7$, respectively, $P=0.007)$. The vehicle arm and the celecoxib single agent arm showed time to progression of 7 (6-10) days, $n=5$ vs $11.5(10-12)$ days, $n=5$, respectively.

To further confirm these results, two additional RCC models were used, the UMRC-3 cell line model and the MDA-62 patient tumour derived model. As shown in Figure 3, celecoxib alone had little impact on the growth rate in these models. The combination of celecoxib and sunitinib also showed improved efficacy $v s$ single agent sunitinib.

Concurrent therapy is superior to sequential therapy. To assess the temporal relationship between sunitinib and celecoxib administration, we compared adding celecoxib vs switching to celecoxib at the time of initial tumour progression on sunitinib in the 786-O model and determined the time to increase by another $2 \mathrm{~mm}$ in long axis. Figure 4 shows that switching to celecoxib (Sunitinib $\rightarrow$ Celecoxib) is significantly worse than continuous sunitinib (sunitinib continuous) (median (range) $10(5-10)$ days, $n=6 \mathrm{vs}$ $12(10-13)$ days, $n=7$, respectively, $P=0.003)$ and that delayed addition of celecoxib (sunitinib $\rightarrow$ celecoxib + sunitinib) (median (range) $10(7-13)$ days, $n=7)$ did not improve the efficacy of continuous sunitinib. Thus, early administration of celecoxib appears to be necessary for it to enhance the efficacy of sunitinib therapy in this model.

Celecoxib augments the activity of sunitinib in an angiogenesisindependent manner. As celecoxib has been shown to exhibit antiangiogenic activities in addition to many other antitumour activities, we first assessed the effects of celecoxib on the antiangiogenic activity of sunitinib. Tumour perfusion was measured in the 786-O tumour model by ASL MRI, a technique which correlates with microvascular density, at days $0,2,4$, and 8 (Figure 5). While sunitinib $(n=2)$ treatment led to a pronounced drop in tumour perfusion at all time points compared with vehicle $(n=3)$, celecoxib $(n=2)$ did not decrease tumour perfusion as a single agent or further decrease perfusion when added to sunitinib $(n=3)$. Although sample sizes are small, preventing statistical
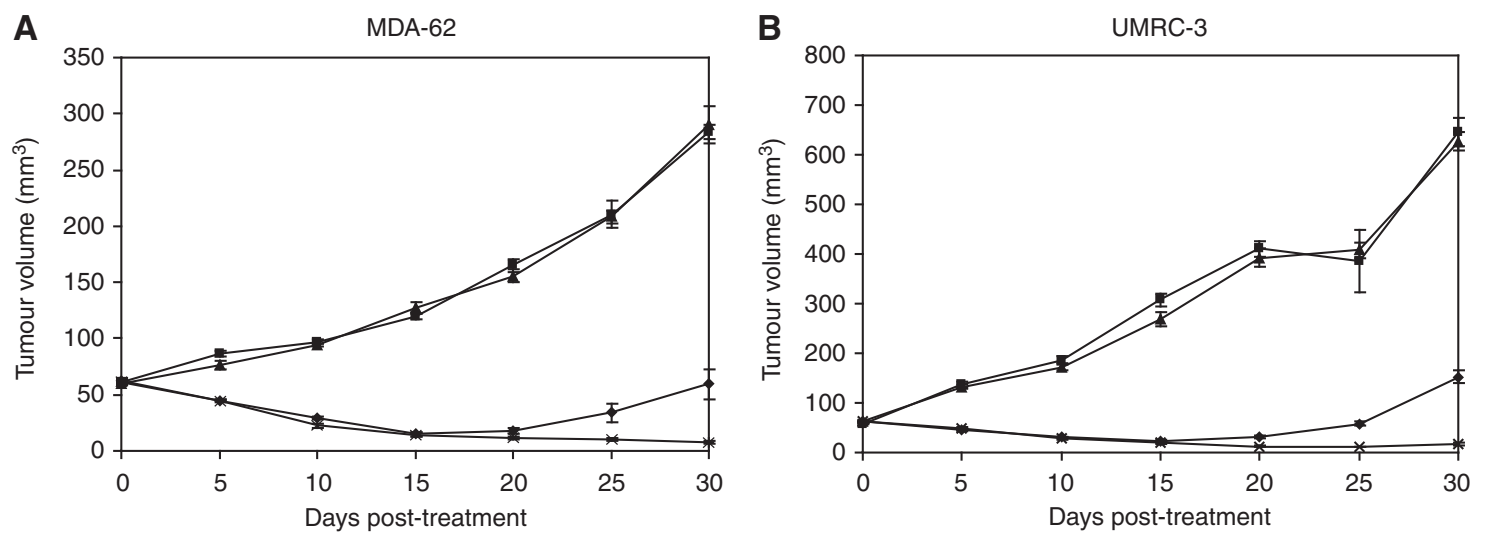

- Vehicle $₫$ Celecoxib $\bullet$ Sunitinib $\star$ Celecoxib+sunitinib

Figure 3. Celecoxib enhances the anti-tumour activity of sunitinib in additional human xenograft clear cell cRCC models. Comparison of volume $\left(\mathrm{mm}^{3}\right)$ over time (days) following treatment with vehicle, celecoxib, sunitinib, or combination of celecoxib and sunitinib, in two different human xenograft cRCC models: MDA-62 (A) and UMRC-3 (B). $N=3$ tumours in each arm. Data are shown as average \pm s.e.m. 


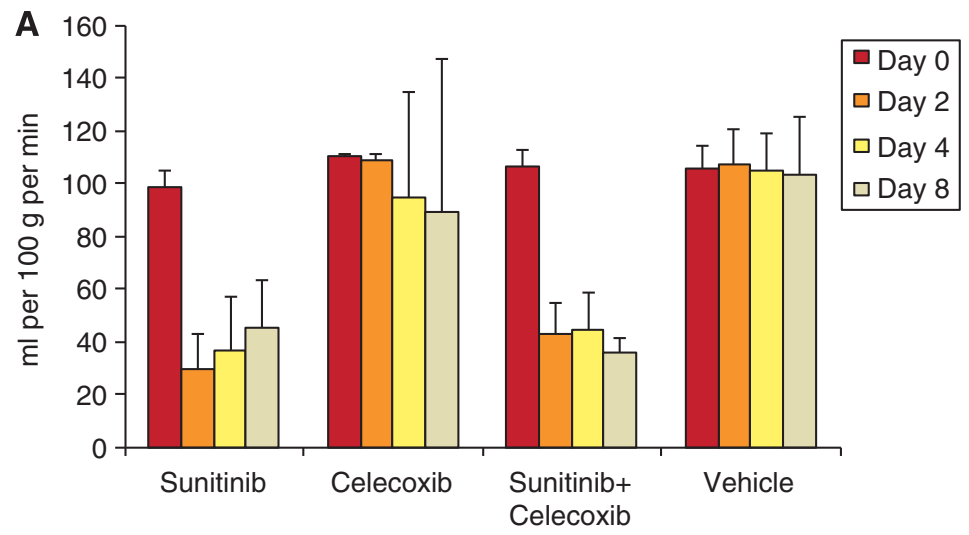

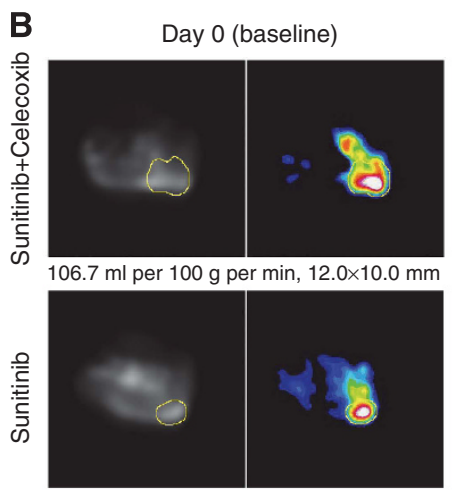

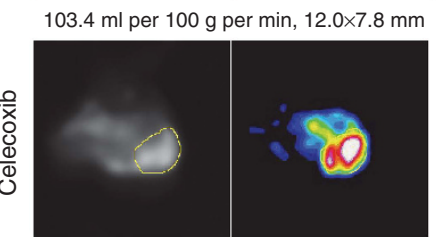

$110.0 \mathrm{ml}$ per $100 \mathrm{~g}$ per $\min , 11.8 \times 10 \mathrm{~mm}$

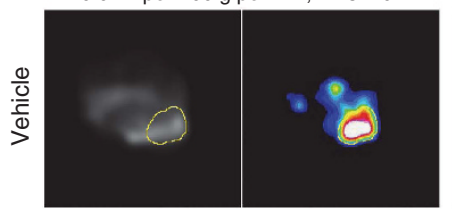

$114.8 \mathrm{ml}$ per $100 \mathrm{~g}$ per $\mathrm{min}, 12.0 \times 10.0 \mathrm{~mm}$
Day 2 (post-treatment)

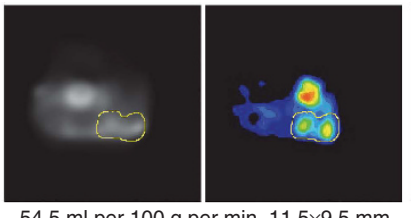

$54.5 \mathrm{ml}$ per $100 \mathrm{~g}$ per min, $11.5 \times 9.5 \mathrm{~mm}$

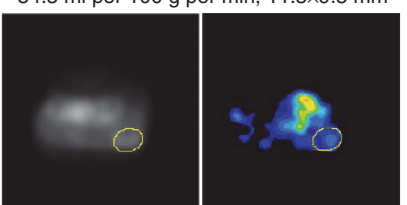

$38.7 \mathrm{ml}$ per $100 \mathrm{~g}$ per min, $11.5 \times 7.0 \mathrm{~mm}$

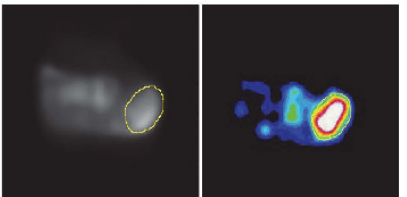

$124.3 \mathrm{ml}$ per $100 \mathrm{~g}$ per min, $11.8 \times 10.0 \mathrm{~mm}$

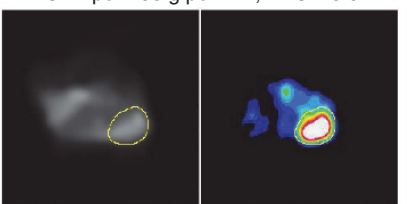

Day 4 (post-treatment)
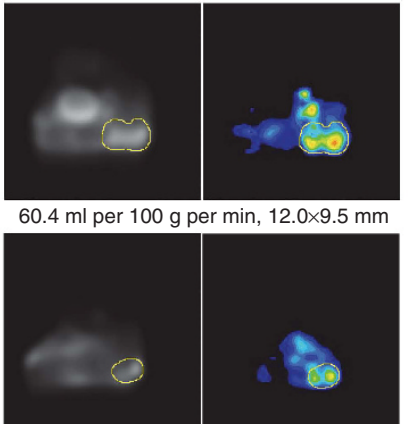

$51.1 \mathrm{ml}$ per $100 \mathrm{~g}$ per $\mathrm{min}, 12.0 \times 7.2 \mathrm{~mm}$

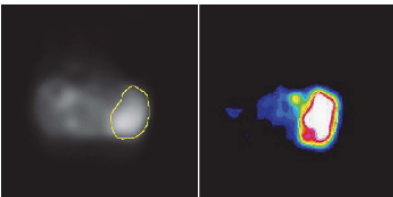

$123.7 \mathrm{ml}$ per $100 \mathrm{~g}$ per $\mathrm{min}, 12.0 \times 10 \mathrm{~mm}$

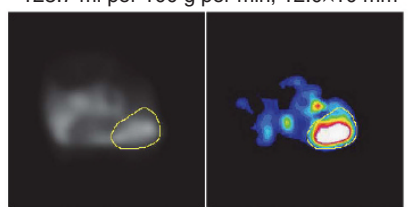

Day 8 (post-treatment)

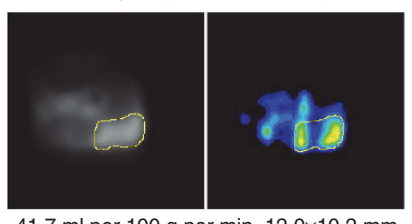

$41.7 \mathrm{ml}$ per $100 \mathrm{~g}$ per min, $12.0 \times 10.2 \mathrm{~mm}$

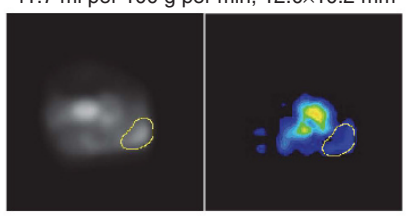

$31.9 \mathrm{ml}$ per $100 \mathrm{~g}$ per min, $13.0 \times 8.0 \mathrm{~mm}$

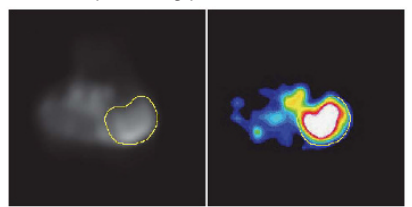

$130.1 \mathrm{ml}$ per $100 \mathrm{~g}$ per min, $13.0 \times 11.0 \mathrm{~mm}$

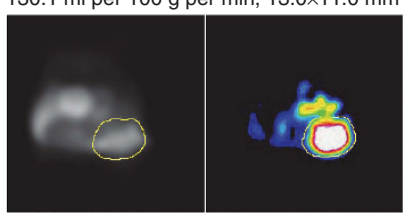

O

$160 \mathrm{ml}$ per $100 \mathrm{~g}$ per min

Figure 5. Measurements of perfusion demonstrate that the celecoxib does not affect perfusion despite significant tumour size effect. Bar graphs of average tumour perfusion as measured by ASL MRI with SD are shown at four time points in (A). The treatment arms are as follows: sunitinib ( $n=2$ ), celecoxib $(n=2)$, sunitinib + celecoxib $(n=3)$, and vehicle $(n=3)$. Representative images from the four treatment arms are shown in (B).

Representative tumour regions are outlined with yellow line in ASL perfusion images (right column of each time point) and the corresponding reference proton density images (left column). The overall tumour size was measured with long and short axes (in mm), one axis is shown in this figure, and the mean blood flow (in $\mathrm{ml}$ per $100 \mathrm{~g}$ per $\mathrm{min}$ ) are shown below each image. A colour bar on bottom represents range of perfusion values from 0 to $160 \mathrm{ml}$ per $100 \mathrm{~g}$ per min.

was obtained directly from a patient undergoing surgery for cRCC, implanted directly into the subcutaneous space of female BALB/c nude mice and serially passaged into new mice without ever being propagated in vitro. Because it is not clonal in origin, but rather developed from a fragment of human tumour, it may be more reflective the heterogeneity in tumour biology associated with the human condition. Although different pretreatment sizes were used in the patient tumour model and xenograft models due to differences in imaging requirements, similar treatment trends were obtained. In general the effects of treatment are more pronounced when tumours are smaller prior to treatment. Further experiments to clarify the differences in effect $v s$ pretreatment sizes should be considered. Experiments with this human tumour model further strengthen the findings noted with the clonally derived cell lines.
COX-2 inhibition has been shown to have antitumour activity in cRCC and is postulated to function via a variety of antitumour and antiangiogenic mechanisms (Chen et al, 2004a and b; Sato et al, 2010). COX-2 expression has also been reported to correlate with cRCC prognosis. Although the precise relationship is not wellunderstood, most published studies report COX-2 expression to correlate with poor clinicopathologic features and predict a poor prognosis (Miyata et al, 2003; Tuna et al, 2004; Sozen et al, 2008; Li et al, 2009). One report, however, found that COX-2 expression predicted for a longer median overall survival (KankuriTammilehto et al, 2010). While it remains unclear how to reconcile these seemingly disparate findings, it is possible that the discrepancies could relate to the clinical context in which the tissue was obtained. In this regard, our studies showing enhanced 
COX-2 expression at the time of sunitinib resistance, particularly adjacent to areas of tumour necrosis, suggest that this expression may be both heterogeneous and inducible as a consequence of VEGFR TKI-induced hypoxia within the cRCC xenografts. In this study we cannot rule out the possibility that COX-2 expression appears to be increasing in areas of hypoxia and actually decreasing in non-hypoxic areas. This possibility is less likely since COX-2 is known to be positively regulated by hypoxia.

COX-2 inhibition has also been studied in clinical trials of patients with advanced cRCC. Rini et al (2006) have examined the relationship between COX-2 expression and response to celecoxib and interferon- $\alpha$ in phase II trials (Schwandt et al, 2011). An initial trial in patients with metastatic cRCC introduced the hypothesis that maximal COX-2 immunostaining may directly correlate with response to the combination (Rini et al, 2006). However, a subsequent study of the combination confined to patients with high COX-2 expressing tumours did not substantiate a significant benefit for the combination relative to interferon alone (Schwandt et al, 2011). Another clinical trial combining the COX-2 inhibitor, meloxicam, and IFN- $\alpha$ in 43 patients with metastatic cRCC showed an overall response rate of $37.2 \%$ with a median time to progression of 14 months (Shinohara et al, 2009). However, at this point, no clinical studies have examined the role of COX-2 inhibition in combination with a VEGFR TKI.

Evasive resistance to antiangiogenic therapy in cRCC is likely multi-factorial. Several potential mechanisms of resistance have recently been reported (Casanovas et al, 2005; Rini and Atkins, 2009; Bhatt et al, 2010; Hammers et al, 2010; Huang et al, 2010). We have shown that VEGFR blockade results in prompt tumour devascularisation and likely hypoxia-driven tumour necrosis(Schor-Bardach et al, 2009). Thus, upregulation of hypoxia-mediated mechanisms of resistance is likely an early event post-VEGFR TKI therapy. Although our prior studies have shown that resumed angiogenesis and restored perfusion was one mechanism of acquired resistance to sunitinib, we did not find that administration of celecoxib led to decreased perfusion by ASL MRI in our models. Thus, celecoxib is likely acting by a distinct mechanism from sunitinib, which potently reduces tumour perfusion. It is conceivable that as VEGFR blockade persists, the mechanisms contributing to resistance become more diverse. Our timing experiments show that the activity of celecoxib depends on dynamic changes induced by sunitinib treatment. Further experiments in tumour models that include tumour cell-endothelial cell interactions are needed and are planned.

Optimally, in the future, application of surrogate biomarkers such as PGE-M, a urinary metabolite of PGE2 (Murphey et al, 2004; Johnson et al, 2006; Reckamp et al, 2011), might enable institution of treatment at the time of COX-2 upregulation, thereby sparing the cost and toxicity associated with upfront combination therapy. If a biomarker for COX-2 activity were available, patients with metastatic RCC being treated with a VEGFR pathway inhibitor could be monitored over the course of therapy and celecoxib added at the time of biomarker elevation and compared with continued VEGFR pathway inhibitor alone. However, in the absence of such biomarkers, our data support the study of the initial combination of celecoxib and sunitinib in patients with advanced cRCC.

\section{ACKNOWLEDGEMENTS}

This work was supported by research grants awarded to RB from the National Institutes of Health/National Cancer Institute (5 K08 CA138900) and the Dana-Farber/Harvard Cancer Centre Kidney SPORE National Cancer Institute (P50CA101942).

\section{REFERENCES}

Alsop DC, Detre JA (1996) Reduced transit-time sensitivity in noninvasive magnetic resonance imaging of human cerebral blood flow. J Cereb Blood Flow Metab 16: 1236-1249.

Arber N, Eagle CJ, Spicak J, Racz I, Dite P, Hajer J, Zavoral M, Lechuga MJ, Gerletti P, Tang J, Rosenstein RB, Macdonald K, Bhadra P, Fowler R, Wittes J, Zauber AG, Solomon SD, Levin B (2006) Celecoxib for the prevention of colorectal adenomatous polyps. N Engl J Med 355: 885-895.

Bhatt RS, Wang X, Zhang L, Collins MP, Signoretti S, Alsop DC, Goldberg SN, Atkins MB, Mier JW (2010) Renal cancer resistance to antiangiogenic therapy is delayed by restoration of angiostatic signaling. Mol Cancer Ther 9: $2793-2802$

Casanovas O, Hicklin D, Bergers G, Hanahan D (2005) Drug resistance by evasion of antiangiogenic targeting of VEGF signaling in late-stage pancreatic islet tumors. Cancer Cell 8: 299-309.

Chen Q, Shinohara N, Abe T, Harabayashi T, Nonomura K (2004a) Impact of cyclooxygenase- 2 gene expression on tumor invasiveness in a human renal cell carcinoma cell line. J Urol 172: 2153-2157.

Chen Q, Shinohara N, Abe T, Watanabe T, Nonomura K, Koyanagi T (2004b) Significance of COX-2 expression in human renal cell carcinoma cell lines. Int J Cancer 108: 825-832.

Farooqui M, Li Y, Rogers T, Poonawala T, Griffin RJ, Song CW, Gupta K (2007) COX-2 inhibitor celecoxib prevents chronic morphine-induced promotion of angiogenesis, tumour growth, metastasis and mortality, without compromising analgesia. Br J Cancer 97: 1523-1531.

Ghosh N, Chaki R, Mandal V, Mandal SC (2010) COX-2 as a target for cancer chemotherapy. Pharmacol Rep 62: 233-244.

Grossman HB, Wedemeyer G, Ren LQ (1985) Human renal carcinoma: characterization of five new cell lines. J Surg Oncol 28: 237-244.

Hammers HJ, Verheul HM, Salumbides B, Sharma R, Rudek M, Jaspers J, Shah P, Ellis L, Shen L, Paesante S, Dykema K, Furge K, Teh BT, Netto G, Pili R (2010) Reversible epithelial to mesenchymal transition and acquired resistance to sunitinib in patients with renal cell carcinoma: evidence from a xenograft study. Mol Cancer Ther 9: 1525-1535.

Hida T, Kozaki K, Muramatsu H, Masuda A, Shimizu S, Mitsudomi T, Sugiura T, Ogawa M, Takahashi T (2000) Cyclooxygenase-2 inhibitor induces apoptosis and enhances cytotoxicity of various anticancer agents in non-small cell lung cancer cell lines. Clin Cancer Res 6: 2006-2011.

Huang D, Ding Y, Zhou M, Rini BI, Petillo D, Qian CN, Kahnoski R, Futreal PA, Furge KA, Teh BT (2010) Interleukin-8 mediates resistance to antiangiogenic agent sunitinib in renal cell carcinoma. Cancer Res 70: 1063-1071.

Johnson JC, Schmidt CR, Shrubsole MJ, Billheimer DD, Joshi PR, Morrow JD, Heslin MJ, Washington MK, Ness RM, Zheng W, Schwartz DA, Coffey RJ, Beauchamp RD, Merchant NB (2006) Urine PGEM: A metabolite of prostaglandin E2 as a potential biomarker of advanced colorectal neoplasia. Clin Gastroenterol Hepatol 4: 1358-1365.

Kankuri-Tammilehto MK, Söderström KO, Pelliniemi TT, Vahlberg T, Pyrhönen SO, Salminen EK (2010) Prognostic evaluation of COX-2 expression in renal cell carcinoma. Anticancer Res 30: 3023-3030.

Karam JA, Zhang XY, Tamboli P, Margulis V, Wang H, Abel EJ, Culp SH, Wood CG (2011) Development and characterization of clinically relevant tumor models from patients with renal cell carcinoma. Eur Urol 59: 619-628.

Legge F, Paglia A, D’Asta M, Fuoco G, Scambia G, Ferrandina G (2011) Phase II study of the combination carboplatin plus celecoxib in heavily pre-treated recurrent ovarian cancer patients. BMC Cancer 11: 214.

Li JF, Chu YW, Wang GM, Zhu TY, Rong RM, Hou J, Xu M (2009) The prognostic value of peritumoral regulatory $\mathrm{T}$ cells and its correlation with intratumoral cyclooxygenase-2 expression in clear cell renal cell carcinoma. BJU Int 103: 399-405.

Li W, Wang J, Jiang HR, Xu XL, Zhang J, Liu ML, Zhai LY (2011) Combined effects of cyclooxygenase-1 and cyclooxygenase-2 selective inhibitors on ovarian carcinoma in vivo. Int J Mol Sci 12: 668-681.

Miyata Y, Koga S, Kanda S, Nishikido M, Hayashi T, Kanetake H (2003) Expression of cyclooxygenase-2 in renal cell carcinoma: correlation with tumor cell proliferation, apoptosis, angiogenesis, expression of matrix metalloproteinase-2, and survival. Clin Cancer Res 9: 1741-1749.

Motzer RJ, Hutson TE, Tomczak P, Michaelson MD, Bukowski RM, Oudard S, Negrier S, Szczylik C, Pili R, Bjarnason GA, Garcia-del-Muro X, Sosman JA, Solska E, Wilding G, Thompson JA, Kim ST, Chen I, Huang X, Figlin 
RA (2009) Overall survival and updated results for sunitinib compared with interferon alfa in patients with metastatic renal cell carcinoma. J Clin Oncol 27: 3584-3590.

Motzer RJ, Nosov D, Eisen T, Bondarenko IN, Lesovoy V, Lipatov ON, Tomczak P, Lyulko AA, Alyasova A, Harza M, Kogan M, Alexeev BY, Sternberg CN, Szczylik C, Zhang J, Strahs AL, Esteves B, Slichenmyer WJ, Berkenblit A, Hutson TE (2012) Tivozanib versus sorafenib as initial targeted therapy for patients with advanced renal cell carcinoma: Results from a phase III randomized, open-label, multicenter trial. J Clin Oncol 30 (Suppl 15; abstr 14501).

Murphey LJ, Williams MK, Sanchez SC, Byrne LM, Csiki I, Oates JA, Johnson DH, Morrow JD (2004) Quantification of the major urinary metabolite of PGE2 by a liquid chromatographic/mass spectrometric assay: determination of cyclooxygenase-specific PGE2 synthesis in healthy humans and those with lung cancer. Anal Biochem 334: 266-275.

Nosov DA, Esteves B, Lipatov ON, Lyulko AA, Anischenko AA, Chacko RT, Doval DC, Strahs A, Slichenmyer WJ, Bhargava P (2012) Antitumor activity and safety of tivozanib (AV-951) in a phase II randomized discontinuation trial in patients with renal cell carcinoma. J Clin Oncol 30: 1678-1685.

Park W, Oh YT, Han JH, Pyo H (2008) Antitumor enhancement of celecoxib, a selective Cyclooxygenase-2 inhibitor, in a Lewis lung carcinoma expressing Cyclooxygenase-2. J Exp Clin Cancer Res 27: 66.

Reckamp K, Gitlitz B, Chen LC, Patel R, Milne G, Syto M, Jezior D, Zaknoen S (2011) Biomarker-based phase I dose-escalation, pharmacokinetic, and pharmacodynamic study of oral apricoxib in combination with erlotinib in advanced nonsmall cell lung cancer. Cancer 117: 809-818.

Rini BI, Atkins MB (2009) Resistance to targeted therapy in renal-cell carcinoma. Lancet Oncol 10: 992-1000.

Rini BI, Escudier B, Tomczak P, Kaprin A, Szczylik C, Hutson TE, Michaelson MD, Gorbunova VA, Gore ME, Rusakov IG, Negrier S, Ou YC, Castellano D, Lim HY, Uemura H, Tarazi J, Cella D, Chen C, Rosbrook B, Kim S, Motzer RJ (2011) Comparative effectiveness of axitinib versus sorafenib in advanced renal cell carcinoma (AXIS): a randomised phase 3 trial. Lancet 378: 1931-1939.

Rini BI, Weinberg V, Dunlap S, Elchinoff A, Yu N, Bok R, Simko J, Small EJ (2006) Maximal COX-2 immunostaining and clinical response to celecoxib and interferon alpha therapy in metastatic renal cell carcinoma. Cancer 106: 566-575.

Sato N, Mizutani Y, Li YN, Fujiwara J, Ishida H, Toiyama D, Abe K, Hayashi I, Nakanishi H, Kawauchi A, Miki T (2010) Enhancement of the sensitivity of renal cell carcinoma cells to fas-mediated cytotoxicity and apoptosis by the selective cyclooxygenase-2 inhibitor JTE-522. Urol Int 84: 362-368.

Schor-Bardach R, Alsop DC, Pedrosa I, Solazzo SA, Wang X, Marquis RP, Atkins MB, Regan M, Signoretti S, Lenkinski RE, Goldberg SN (2009) Does arterial spin-labeling MR imaging-measured tumor perfusion correlate with renal cell cancer response to antiangiogenic therapy in a mouse model? Radiology 251: 731-742.

Schwandt A, Garcia JA, Elson P, Wyckhouse J, Finke JH, Ireland J, Triozzi P, Zhou M, Dreicer R, Rini BI (2011) Clinical and immunomodulatory effects of celecoxib plus interferon-alpha in metastatic renal cell carcinoma patients with COX-2 tumor immunostaining. J Clin Immunol 31: 690-698.

Shinohara N, Kumagai A, Kanagawa K, Maruyama S, Abe T, Sazawa A, Nonomura K (2009) Multicenter phase II trial of combination therapy with meloxicam, a cox-2 inhibitor, and natural interferon-alpha for metastatic renal cell carcinoma. Jpn J Clin Oncol 39: 720-726.

Song X, Lin HP, Johnson AJ, Tseng PH, Yang YT, Kulp SK, Chen CS (2002) Cyclooxygenase-2, player or spectator in cyclooxygenase-2 inhibitorinduced apoptosis in prostate cancer cells. J Natl Cancer Inst 94: 585-591.

Sozen S, Gurocak S, Erdem O, Acar C, Kordan Y, Akyol G, Alkibay T (2008) Cyclooxygenase-2 expression: does it have a probable role in tumorigenesis mechanisms of renal cell carcinoma? Int Urol Nephrol 40: 295-301.

Sternberg CN, Davis ID, Mardiak J, Szczylik C, Lee E, Wagstaff J, Barrios CH, Salman P, Gladkov OA, Kavina A, Zarbá JJ, Chen M, McCann L, Pandite L, Roychowdhury DF, Hawkins RE (2010) Pazopanib in locally advanced or metastatic renal cell carcinoma: results of a randomized phase III trial. J Clin Oncol 28: 1061-1068.

Tuna B, Yorukoglu K, Gurel D, Mungan U, Kirkali Z (2004) Significance of COX-2 expression in human renal cell carcinoma. Urology 64: 1116-1120.

Veltman JD, Lambers ME, van Nimwegen M, Hendriks RW, Hoogsteden HC, Aerts JG, Hegmans JP (2010) COX-2 inhibition improves immunotherapy and is associated with decreased numbers of myeloid-derived suppressor cells in mesothelioma. Celecoxib influences MDSC function. BMC Cancer 10: 464 .

Vivaldi A, Ciampi R, Tacito A, Molinaro E, Agate L, Bottici V, Pinchera A, Collecchi P, Elisei R (2012) Celecoxib a cyclooxygenase-2 inhibitor, potentiates the chemotherapic effect of vinorelbine in the medullary thyroid cancer TT cell line. Mol Cell Endocrinol 355: 41-48.

Zhang L, Bhasin M, Schor-Bardach R, Wang X, Collins MP, Panka D, Putheti P, Signoretti S, Alsop DC, Libermann T, Atkins MB, Mier JW, Goldberg SN, Bhatt RS (2011) Resistance of renal cell carcinoma to sorafenib is mediated by potentially reversible gene expression. PLoS One 6: e19144.

(c) (i) (2) This work is licensed under the Creative Commons cc) Attribution-NonCommercial-Share Alike 3.0 Unported License. To view a copy of this license, visit http://creativecommons. org/licenses/by-nc-sa/3.0/ 